\title{
SPATIO-TEMPORAL ANALYSIS AND MODELING OF URBAN GROWTH OF BIRATNAGAR CITY, NEPAL
}

\author{
S. Shrestha \\ Photogrammetry and Remote Sensing Unit, Land Management Training Center, Government of Nepal - shr.sanjeevan@gmail.com
}

\author{
Commission V, WG V/7 \& Commission IV, WG IV/6
}

\begin{abstract}
KEY WORDS: Urban Growth, Image Classification, Spatial Metrics, Analytical Hierarchical Process, Multi-Criteria Analysis, Land Use Modeling
\end{abstract}

\begin{abstract}
:
Increasing land use land cover changes, especially urban growth has put a negative impact on biodiversity and ecological process. As a consequences, they are creating a major impact on the global climate change. There is a recent concern on the necessity of exploring the cause of urban growth with its prediction in future and consequences caused by this for sustainable development. This can be achieved by using multitemporal remote sensing imagery analysis, spatial metrics, and modeling. In this study, spatio-temporal urban change analysis and modeling were performed for Biratnagar City and its surrounding area in Nepal. Land use land cover map of 2004, 2010, and 2016 were prepared using Landsat TM imagery using supervised classification based on support vector machine classifier. Urban change dynamics, in term of quantity, and pattern was measured and analyzed using selected spatial metrics and using Shannon's entropy index. The result showed that there is increasing trend of urban sprawl and showed infill characteristics of urban expansion. Projected land use land cover map of 2020 was modeled using cellular automata-based approach. The predictive power of the model was validated using kappa statistics. Spatial distribution of urban expansion in projected land use land cover map showed that there is increasing threat of urban expansion on agricultural land.
\end{abstract}

\section{INTRODUCTION}

Accelerating land use land cover (LULC) changes, especially urban growth has been profound these days, putting a negative impact on biodiversity, ecological process, thus creating a serious impact on the global climate change (Bihamta et al., 2015; Zhang et al., 2014). In last few decades, there has been substantial growth in urban areas, especially in the developing countries. According to United Nations ("World Urbanization Prospects," 2014), 54 percent of people around the world were residing in the urban area, and two-thirds of world's population is projected to be in the urban area by 2050 . Due to increased availability of education, employment, services, production, sophisticated life, in developing country like Nepal, urbanization is considered as a usual phenomenon of economic growth as well as social change. But unplanned/haphazard urbanization may trigger many problems in a long run, failing sustainable city development. Nepal is one of the ten least urbanized countries, but one of the fastest urbanizing country in the world, with the rate of urbanization of 3 percent (Bakrania, 2012). Among which, Biratnagar city is one of the densely populated areas and has a higher rate of urbanization after Kathmandu and Pokhara city.

There is a major concern on the necessity of exploring the causes of urban growth with its prediction in future and consequence caused by this for sustainable development. Due to rapid advancement in remote sensing (RS) and geographic information system (GIS) resources, tools and methods have enhanced researcher to apply the technique for monitoring and modeling urban sprawl, land use dynamics and urbanization effectively (Araya \& Cabral, 2010; Tewolde \& Cabral, 2011). Numerous researches has been conducted by several scholars focusing on the urban change phenomenon of urban sprawl using the utility of Cellular Automata (CA) Markov, Markov Chain, Artificial Neural Network (ANN), SLEUTH (Bihamta et al., 2015). Among them, CA model has been proven best for modeling urban pattern and phenomenon (Thapa \& Murayama, 2011; Zhang et al., 2014). Many studies (Araya \& Cabral, 2010; Bihamta et al., 2015; Tewolde \& Cabral, 2011; Thapa \& Murayama, 2011; Zhang et al., 2014) have shown that complex behaviour of urban change can be effectively simulated in the CA-based model. Its natural affinity with GIS and RS data gives more advantage to a user for simulating urban expansion. Moreover, its capability to integrate spatial multicriteria analysis (MCE) along with analytic hierarchical process (AHP) makes it more potential to model urban dynamics (Sakieh et al., 2014).

In this study, quantification and analysis of Biratnagar city's urban growth changes and spatial pattern of urban area have been performed using an integrated approach of GIS and RS technique for the time period, 2004-2016. Similarly, probable urban growth area was simulated for future years using cellular automata (CA) model, using several factors affecting the urban growth and the past urban growth trend of the city. This study simulated and quantified the changing pattern of urban growth and future urbanization so that responsible authority could make it useful for implementing appropriate policies and monitoring mechanism for sustainable development. The paper is an example of reproducibility of existing technique of urban growth simulation in completely new study area (i.e. Biratnagar).

\section{STUDY AREA}

The study area (figure 1) lies in the south-eastern part of Morang district of Koshi region of Nepal. It consists of Biratnagar municipality and its surrounding VDCs (small administrative boundary) named as Tankisinuwari, Baijanathpur, Ramganj Belgachhi, Katahari, Matigachha and Buddhanagar. The geographic extension of the area is $26^{\circ} 21^{\prime} 2.5^{\prime \prime} \mathrm{N}$ to $26^{\circ} 32^{\prime}$ $53.2^{\prime \prime} \mathrm{N}$ in latitude and $87^{\circ} 14^{\prime} 18.6^{\prime \prime} \mathrm{E}$ to $87^{\circ} 21^{\prime} 45.7^{\prime \prime} \mathrm{E}$ in longitude. It covers an area of $149.126 \mathrm{sq}$. $\mathrm{km}$. It is the second largest city next to the capital city, Kathmandu, and it consists of 
one of the biggest industrial areas in the country. It accounts for the highest growth rate of population among designated town in the country and there is a rapid change in land use.

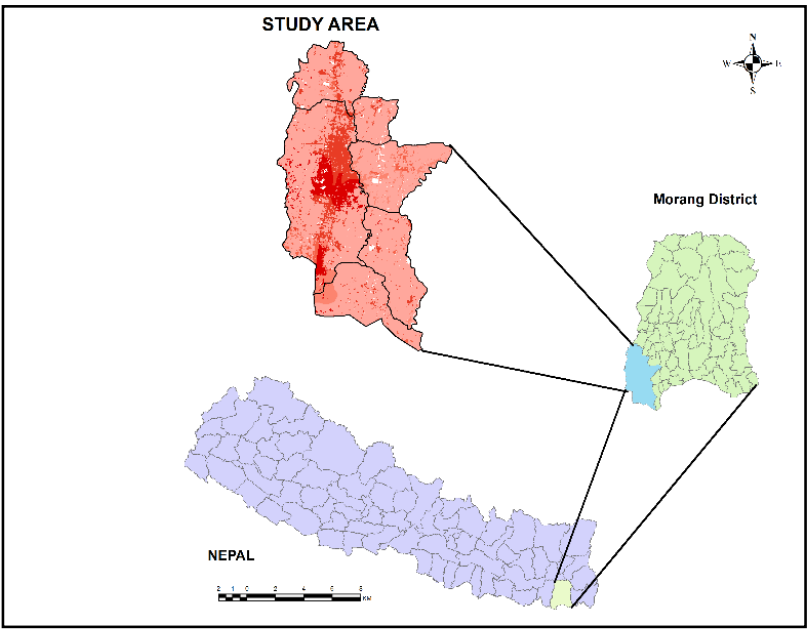

Figure 1. Location map of study area

\section{DATA}

Three Landsat TM satellite imagery with $30 \mathrm{~m}$ resolution, acquired in November 2004, October 2010 and October 2016 were used, obtained from the United States Geological Survey (USGS) (http://glovis.usgs.gov/) in the standard format. The image was projected into a World Geodetic System (WGS) 1984, Universal Transverse Mercator (UTM), Zone 45N coordinate system.

Landcover data, main roads, main rivers, topographic layers (contour and spot height) were obtained from Survey Department, Ministry of Land Management, Cooperatives and Poverty Alleviation, Nepal; whereas population data were obtained from the Central Bureau of Statistics (CBS), Nepal. Google Earth image (time slide) has been used for accuracy assessment.

\section{METHODOLOGY}

The study uses three techniques namely remote sensing, spatial metrics and land use modelling were employed.

\subsection{Preparation of LULC Map using Remote Sensing}

4.1.1 Image Processing: Firstly, pre-processing of acquired images was done using QGIS 2.16, which comprises a geometric transformation, radiometric correction, and image enhancement techniques to improve a quality of an image. Line stripping in Landsat 7 ETM+ (2004 and 2010) was corrected. Normalized indices such as normalized difference vegetation index (NDVI), normalized difference water index (NDWI), and normalized difference built-up index (NDBI) was prepared and used with other available bands in the layer stacking for better characterization of land use land cover type.
4.1.2 LULC Classification and Accuracy Assessment: A classification scheme with supervised classification was developed to obtain a broad level of classification to derive five LULC classes, such as urban area, water bodies, cultivation area, shrub/garden, and fallow land/industrial area. Support vector machine (SVM) classifier with radial basis function (RBF) kernel type was used to classify images. A focal majority filter was used to eliminate small and isolated area presented in a classified image. For accuracy assessment, sample points for each class were generated using stratified random sampling and checked against the google earth imageries. The reliability of classification was checked using overall accuracy metrics.

\subsection{Spatial Metrics and Urban Sprawl Measurement}

4.2.1 Spatial Metrics: Spatial metrics is a key parameter for the description of spatial structure and pattern, through spatial characteristics of patches, class and entire landscape (Herold et al., 2003). Quantification of change in urban structure can be accomplished by using information obtained from spatial matrices (Araya \& Cabral, 2010). For this purpose, LULC map was reclassified into urban and nonurban areas, for a period of 2004 to 2016. Landscape heterogeneity for urban and non-urban classes was measured and analyzed using the FRAGSTATS tool. Seven spatial metrics (CA, NP, ED, LPI, MNN, AWMPFD and CONTAG) was selected (table 1) for analyzing urban changes due to their simplicity and effectiveness in depicting urban change (Araya \& Cabral, 2010; Herold et al., 2003; McGarigal et al., 2002).

\begin{tabular}{|c|c|c|c|}
\hline Metric & Description & Unit & Range \\
\hline $\begin{array}{l}\text { CA- Class } \\
\text { area }\end{array}$ & $\begin{array}{l}\text { Total urban area } \\
\text { in the landscape }\end{array}$ & Hectares & $\begin{array}{l}\mathrm{CA}>0 \text {, no } \\
\text { limit }\end{array}$ \\
\hline $\begin{array}{l}\text { NP- Number } \\
\text { of Patches }\end{array}$ & $\begin{array}{l}\text { Number of urban } \\
\text { patches in the } \\
\text { landscape }\end{array}$ & None & $\begin{array}{l}\mathrm{NP}>=1, \text { no } \\
\text { limit }\end{array}$ \\
\hline $\begin{array}{l}\text { ED- Edge } \\
\text { density }\end{array}$ & $\begin{array}{l}\text { Sum of length of } \\
\text { all edge segment } \\
\text { involving the } \\
\text { urban patch }\end{array}$ & $\begin{array}{l}\text { Meter } \\
\text { per } \\
\text { hectares }\end{array}$ & $\begin{array}{l}\mathrm{ED}>=0, \text { no } \\
\text { limit }\end{array}$ \\
\hline $\begin{array}{l}\text { LPI- Largest } \\
\text { patch index }\end{array}$ & $\begin{array}{l}\text { Percentage } \\
\text { proportion of } \\
\text { area of largest } \\
\text { patch of urban }\end{array}$ & percent & $\begin{array}{l}0<=\text { LPI }<= \\
100\end{array}$ \\
\hline $\begin{array}{l}\text { MNN- } \\
\text { Euclidean } \\
\text { mean nearest } \\
\text { neighbor } \\
\text { distance }\end{array}$ & $\begin{array}{l}\text { Distance mean } \\
\text { value of all urban } \\
\text { patch from the } \\
\text { nearest } \\
\text { neighboring } \\
\text { patches of same }\end{array}$ & meter & $\begin{array}{l}\text { MNN >0, } \\
\text { no limit }\end{array}$ \\
\hline $\begin{array}{l}\text { AWMPFD- } \\
\text { Area } \\
\text { weighted } \\
\text { mean patch } \\
\text { fractal } \\
\text { dimension }\end{array}$ & $\begin{array}{l}\text { Area weighted } \\
\text { mean value of the } \\
\text { fractal dimension } \\
\text { values of all } \\
\text { urban patches, } \\
\text { the fractal } \\
\text { dimension of a } \\
\text { patch equals two } \\
\text { times the } \\
\text { logarithm of } \\
\text { patch perimeter } \\
\text { (m) divided by } \\
\text { the logarithm of } \\
\text { patch area }\end{array}$ & None & $\begin{array}{l}1<= \\
\text { AWMPFD } \\
<=2\end{array}$ \\
\hline
\end{tabular}




\begin{tabular}{|l|l|l|l|}
\hline CONTAG- & $\begin{array}{l}\text { Heterogeneity of } \\
\text { Contagion }\end{array}$ & $\begin{array}{l}\text { percent } \\
\text { measuring extent } \\
\text { to which } \\
\text { landscapes are } \\
\text { aggregated or } \\
\text { clumped }\end{array}$ & CONTAG \\
$<=100$ \\
\hline
\end{tabular}

Table 1. Spatial metrics used in the study

4.2.2 Urban Sprawl Measurement Using Shannon's Entropy: Urban sprawl is a complex phenomenon having environmental as well as social impacts (Sun et al., 2007). Due to its complex nature, there is no specific, measurable, and universally acceptable measurement method of urban sprawl. Shannon's entropy with its integration with GIS is one of the effective methods used by several scholars (Araya \& Cabral, 2010; Sun et al., 2007). Shannon's entropy is used due to its toughness in urban sprawl measurement and its ability to measure the various patterns of urban area i.e. dispersed and concentrated over time (Yeh and $\mathrm{Li}, 2001$ ). In this study, urban sprawl over a period of 12 years $(2004,2010$ and 2016) has been determined by Shannon entropy calculation. The relative entropy is given by,

$$
E_{n}=\sum_{i=1}^{n} P_{i} \log \left(\frac{1}{P_{i}}\right) / \log (n
$$

Where, $\quad P_{i}=x_{i} / \sum_{i}^{n} x_{i}$

$x_{i}=$ the density of land development, which equals the amount of urban area divided by total amount of land in ith zone in the total of $n$ zones.

The number of a zone is determined by a number of buffer zones around the city centre. In this study, this number is 13 having 1 kilometre of concentric rings around the main core area of the study area. This value ranges from 0 to 1 and determines the distribution of urban sprawl.

The difference in entropy between two time periods can be used to indicate the change in a degree of distribution of urban sprawl, which can be determined as;

$$
\Delta E_{n}=E_{n}(t+1)-E_{n}(t)
$$

Where $E_{n}=$ the difference of relative entropy over two time periods

$E_{n}(t+1)=$ the relative entropy at time period $\mathrm{t}+1$ $E_{n}(t)=$ the relative entropy value at time $\mathrm{t}$ (Sun et al., 2007).

The difference of relative entropy over the period 2004-2010 and 2010-2016 were calculated.

\subsection{Urban Land Use Change Modeling using CA-Markov}

4.3.1 AHP Based MCE for CA-Markov Analysis: CA-Markov is combined cellular automata/Markov chain/multicriteria land use land cover prediction model that takes consideration of spatial distribution as well as spatial contiguity in a space (Sang et al., 2011). Urban sprawl modeling using CA-Markov process was mainly done by integrating Markov chain analysis with cellular automata. Markov chain analysis develops transition probability matrix of each land use land cover classes between $\mathrm{t} 1$ time and t 2 time, describing the probability of land cover changes from one period to another (Araya \& Cabral, 2010; Eastman, 2006).

The main disadvantage of this process is that it doesn't consider the spatial behavior of each land use land cover classes over the space. This is the main factor where CA-Markov technique comes to play (Eastman, 2006). CA-Markov model is commonly used models among other LULC models due to its ability to model both spatial and temporal changes. Additionally, characterization of dynamics of LULC, urban sprawl, forest cover, plant growth etc. can be effectively done using CAMarkov model (Ghosh et al., 2017). CA-Markov analysis is backed up by using AHP based multi-criteria analysis to make the analysis more realistic by taking decision from the experts from various sectors influencing the urban land use change analysis. CA-Markov (combination of cellular automata with Markovian approach) predicts urban sprawl using Markov transition matrix, a suitability map and a neighborhood filter (Araya \& Cabral, 2010; Eastman, 2006; Sang et al., 2011).

This study adopted CA-Markov chain analysis technique that is integrated within IDRISI software. Firstly, transition probability matrix for each LULC classes between 2004 and 2010 was prepared using Markov chain analysis. The suitability map for the urban area, agriculture and forest were generated using MCEAHP process and that for water bodies and fallow land were generated with Euclidean distance function considering that closely existing LULC classes have more chance of changing into same classes. Here, socio-economic data (road network, settlement, land cover, population density, and water bodies) were integrated with biophysical data (DEM, slope) of study area through Multicriteria (MCE) technique, as an input for CAMarkov analysis. It is imperative to develop criteria for making decision to determine, which LULC classes are suitable for changing from one class to another with time and space including proximity from road, settlement, water bodies, socio-economic drivers (population density) as well as biophysical factors (DEM, slope) (R.R. Regmi, S.K. Saha, 2014). Depending upon the characteristics of each LULC classes with factors, a fuzzy rule is applied with each factor with fuzzy factor standardization (suitability of a contiguous range of $0=$ least suitable to $255=$ most suitable) for MCE in ArcGIS. For MCE-AHP process, weight for each factor for MCE has been computed from the AHP process. AHP process generally extracts from the measurement through pairwise comparison of each factor and relies on the judgment of experts to derive priority scales. The major strength of AHP is that it deals with judgmental consistency for subjective judgment done by experts (Thapa \& Murayama, 2010). The consistency ratio of each AHP weight was tested and a ratio of less than 0.10 was accepted for decision making through multicriteria evaluation (Thapa \& Murayama, 2010). In AHP process, each criterion of a factor was evaluated with pairwise comparison in decision support system tool in Idrisi. The suitability map of LULC classes of urban, agriculture and shrub were prepared by using the weights with different related factor map in ArcGIS environment.

4.3.1 Model Implementation, Validation and Projection: The predicted LULC map in 2016 using CA-Markov was accomplished with LULC map of 2010 as a base map with standardized group suitability map collection and Markov transition probability area matrix from Markov chain analysis and $5 * 5$ contiguity filters.

Model validation is imperative in modeling process to assessing the performance of land use change model (Pontius et al., 2000). 
In this study, this was done by comparing the result of simulation of LULC 2016 with reference LULC map of 2016 and calculating kappa variations, namely kappa for location (Klocation), kappa for quantity (Kquantity) and kappa for no information (Kno). Klocation defines success due to simulation's ability to indicate location divided by the maximum possible success due to a simulation's ability to specify location perfectly; Kquantity is a measure of validation of the simulation to predict quantity accurately and Kno shows the proportion classified correctly relative to expected proportion classified correctly by a simulation without the ability to indicate accurately quantity or location(Pontius et al., 2000; Tewolde \& Cabral, 2011). More than $80 \%$ accuracy signifies that predictive power of the model is strong (Tewolde \& Cabral, 2011). This means the model is good enough to predict future urban growth (for our case for 2020), assuming transition mechanism between 2004 and 2010 is going to be repeated.

\section{RESULTS AND DISCUSSIONS}

\subsection{Land Use Classification and Accuracy Assessment}

Using supervised with kernel-based support vector machine (SVM) classifier, LULC map of Biratnagar city for the year of 2004, 2010 and 2016 was prepared. LULC map contains five different class namely urban, water bodies, cultivation land, shrub/garden, and fallow land/industrial land. The maps showed that urban and cultivation land covered majority part of the study area.

To check the reliability of classification and to validate the result for further change analysis, the overall accuracy classification scheme was used. Overall accuracies obtained for the maps of 2004, 2010 and 2016 were $84.51 \%, 81.18 \%$, and $84.3 \%$ respectively.

\subsection{Analysis of Spatial Metrics}

Spatial metrics and their variation were calculated for the urban areas for a period of 2004 to 2016 (table 2). The class area metrics show that there is a continuous expansion of urban area for the period of 2004 to 2016. Urban area increased by 468 hectares over a period of 2004-2010 and this increment nearly doubled in a period of 2010-2016. As study area contains a metropolitan city, it is a result of a common process which can be associated with the availability of resources, services, infrastructure, and trade.

The NP increased by $15 \%$ over a period of 2004-2010 and decreased considerably (56\%) in a period of 2010-2016, showing characteristics of urbanization as infill type. This signifies that urbanization was characterized by dispersion with a development of isolated and discontinuous built up area for the first period. In the second period, decrement indicates that these pre-existing isolated urban areas clustered together to form bigger patches. This kind of characteristics of urban growth is also confirmed by changing pattern of ED, with an increment (17\%) in the first period and decrement $(13 \%)$ in the second period. The LPI showed increased tendency over the study period, with an increment of $34 \%$ and $40 \%$ between 2004 to 2010 and 2010 to 2016 respectively. This indicates that the historical core area is still showing considerable growth.

There is a decrease in MNN for both periods i.e. 2004-2010 and 2010-2016, but by the small amount with $1 \%$ and $4 \%$ for the first and second period respectively. This reveals a decrease in distance between urban patches, hence towards agglomeration.
AWMPFD showed increasing trend over the period of 20042016, which also favors the argument toward urban growth. Nevertheless, this value is always slightly higher than 1 , indicating moderate shape complexity. CONTAG decreased with $12 \%$ and $11 \%$ for the period of 2004-2010 and 2010-2016, which signifies that urban area is becoming more homogenous than previous, due to infill characteristics of urban growth trend.

\begin{tabular}{|l|l|l|l|l|l|}
\hline \multirow{2}{*}{ Metrics } & \multicolumn{3}{|c|}{ Year } & \multicolumn{2}{c|}{$\begin{array}{l}\text { Changes in Urban Area } \\
(\%)\end{array}$} \\
\hline & 2004 & 2010 & 2016 & $\begin{array}{l}2004- \\
2010\end{array}$ & $\begin{array}{l}2010- \\
2016\end{array}$ \\
\hline CA & 2260.080 & 2727.540 & 3561.480 & $\begin{array}{l}467.46 \\
(17.1 \%)\end{array}$ & $\begin{array}{l}833.94 \\
(23.4 \%)\end{array}$ \\
\hline NP & 1250.000 & 1466.000 & 939.000 & $\begin{array}{l}216.000 \\
(14.7 \%)\end{array}$ & $\begin{array}{l}-527.000 \\
(-56.1 \%)\end{array}$ \\
\hline ED & 42.135 & 50.523 & 44.810 & $\begin{array}{l}8.390 \\
(16.6 \%)\end{array}$ & $\begin{array}{l}-5.710 \\
(-12.7 \%)\end{array}$ \\
\hline LPI & 7.342 & 11.091 & 18.318 & $\begin{array}{l}3.750 \\
(33.8 \%)\end{array}$ & $\begin{array}{l}7.230 \\
(39.5 \%)\end{array}$ \\
\hline MNN & 69.799 & 69.091 & 65.970 & $\begin{array}{l}-0.710 \\
1 \%)\end{array}$ & $\begin{array}{l}-3.120 \\
(-4.7 \%)\end{array}$ \\
\hline AWMPFD & 1.205 & 1.233 & 1.257 & $\begin{array}{l}0.030 \\
(2.3 \%)\end{array}$ & $\begin{array}{l}0.020 \\
(1.9 \%)\end{array}$ \\
\hline CONTAG & 53.921 & 47.834 & 43.302 & $\begin{array}{l}-6.090 \\
12.7 \%)\end{array}$ & $\begin{array}{l}-4.530 \\
(-10.5 \%)\end{array}$ \\
\hline
\end{tabular}

Table 2. Spatial metrics and their changes in the study area

\subsection{Urban Sprawl Measurement}

The Shannon entropy of the urban areas in 2004, 2010 and 2016 was obtained as $0.824,0.826$ and 0.839 respectively (Table 3 ). All the values are above 0.5 showing a high rate of urban sprawl. Also, there is a continuous increasing trend of urban sprawl from 2004 till 2016. This confirms that urban growth is spreading over core urban area towards the surrounding rural areas. The spatial distribution of urban area (figure 5) over the period of 12 years showed that the there is significant growth of urban area in the north to south direction along major transportation network and around a periphery of the core area.

\begin{tabular}{|l|l|l|l|l|}
\hline $\begin{array}{l}\boldsymbol{E}_{n} \text { (Entropy during 3 study } \\
\text { period) }\end{array}$ & $\begin{array}{l}\Delta \boldsymbol{E}_{n} \text { (Difference in } \\
\text { Entropy) }\end{array}$ \\
\hline 2004 & 2010 & 2016 & $2004-2010$ & $2010-2016$ \\
\hline 0.824 & 0.826 & 0.839 & 0.002 & 0.013 \\
\hline
\end{tabular}

Table 3. Shannon's entropy value and change in entropy

\subsection{Land Use Modeling and Validation}

Simulated LULC map of 2016 after modeling using CA Markov analysis shows reasonably similar spatial distribution to the real LULC of 2016 (figure 2). Validation has been done based on the kappa index of agreement. The $\mathrm{K}_{\mathrm{no}}$, which is analogous with overall accuracy, is calculated to be $85.09 \%$. The model appeared to perform better in predicting specific location and quantity 
accurately $\left(\mathrm{K}_{\text {location }}=0.8469\right.$ and $\mathrm{K}_{\text {quantity }}=0.8013$ respectively $)$. However, kappa statistics heavily depends on the reliability of suitability map collection, result from classification and contiguity matrix used.
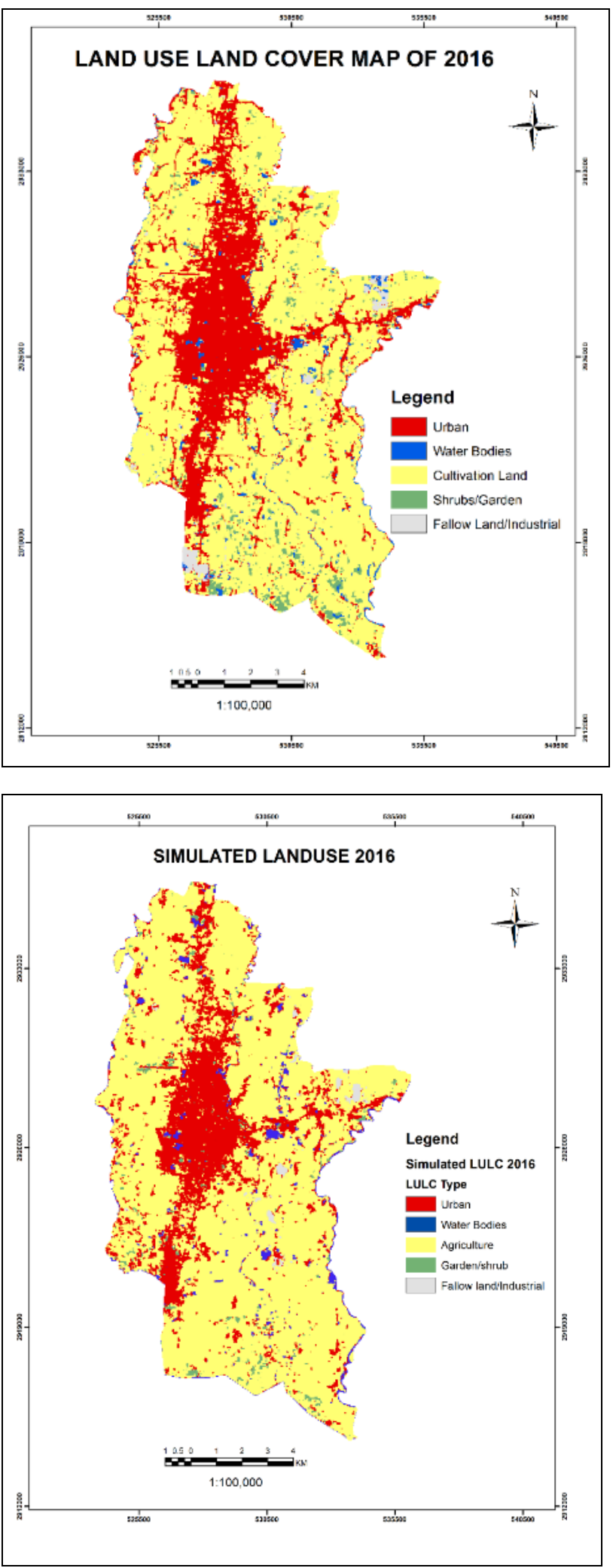

Figure 2. Actual and simulated land use land cover map of 2016

\subsection{Land Use Projection}

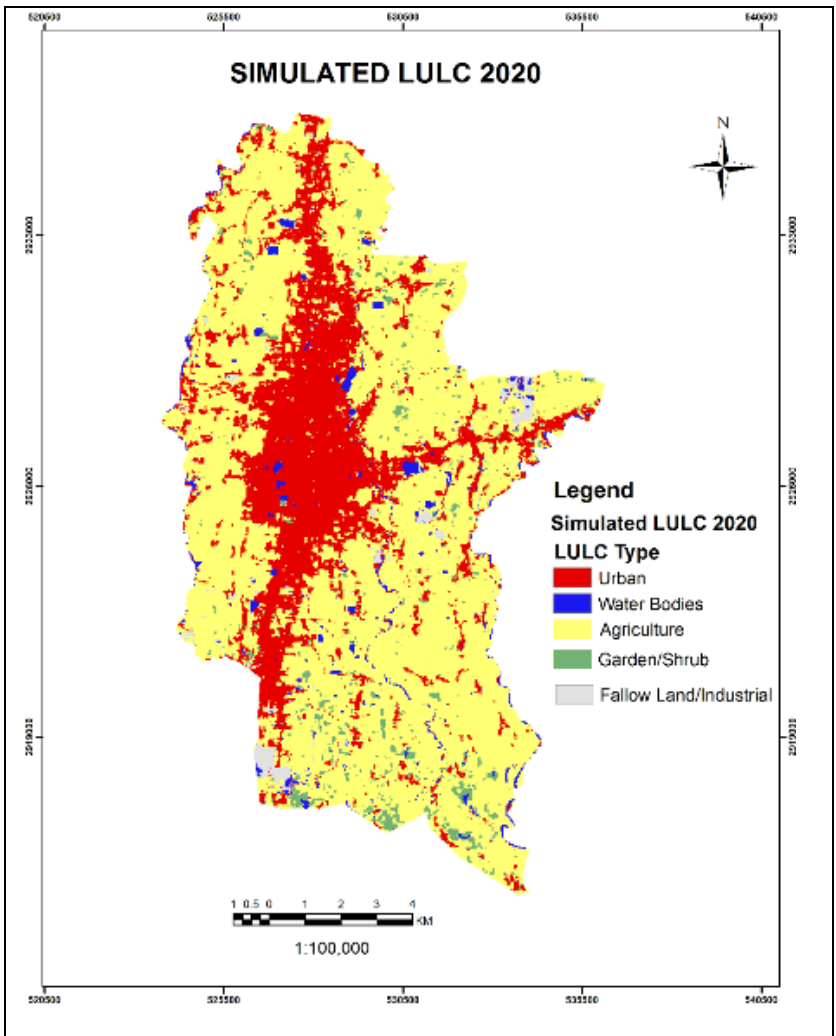

Figure 3. projected land use land cover map of 2020

A land use projection for the year 2020 was performed in the similar way, which is shown in figure 3 . This shows that urban growth might continue to expand in future. The major growth in urban area is further expected to increase in the direction of north to south direction along the major transportation network. The extent of market centered urban area doesn't seem to increase may be due to saturation of that area. The impact of the increase in urban area contributed in rapid reduction in the cultivation land.

\section{CONCLUSION}

The study analyses and models the trend of spatiotemporal change of urban of Biratnagar city and its surrounding areas using the combination of GIS, remote sensing, and modeling techniques. LULC maps of the study area for 2004, 2010 and 2016 were prepared by using supervised classification with kernel-based support vector machine (SVM) classifier. Accuracy assessment was done for validation of classification results.

The nature of urban area changes was quantified and analyzed using spatial metrics after urban areas were extracted from each LULC map. The result from spatial metrics in combination with urban sprawl measurement using Shannon's entropy suggested that there is a high rate of urban sprawl and expansion over the study area. The spatial distribution of urban area suggested that significant growth of urban area in the north to south direction along major transportation network and around a periphery of the core area.

The validation result of a model using kappa degree of agreement showed satisfactory results, which allowed us to project LULC map for 2020. The result shows that urban area might continue to 
grow. So, proper, and timely planning and actions should be implemented.

\section{REFERENCES}

Araya, Y. H., \& Cabral, P., 2010. Analysis and modeling of urban land cover change in Setubal and Sesimbra, Portugal. Remote Sensing, 2(6), 1549-1563. http://doi.org/10.3390/rs2061549

Bakrania, S., 2012. Urbanisation and Urban Growth, 29. www.gsdrc.org (10 Dec 2016)

Bihamta, N., Soffianian, A., Fakheran, S., \& Gholamalifard, M., 2015. Using the SLEUTH Urban Growth Model to Simulate Future Urban Expansion of the Isfahan Metropolitan Area, Iran. Journal of the Indian Society of Remote Sensing, 43(2), 407-414. http://doi.org/10.1007/s12524-014-0402-8

Eastman, J. R., 2006. Guide to GIS and Image Processing. Clark University: Worcester, MA, USA, 1(May), pp. 87-131.

Ghosh, P.; Mukhopadhyay, A.; Chanda, A.; Mondal, P.; Akhand, A.; Mukherjee, S.; Nayak, S.K.; Ghosh, S.;Mitra, D.; Ghosh, T.; et al., 2017. Application of Cellular automata and Markov-chain model in geospatial environmental modeling - A review. Remote Sens. Appl. Soc. Environ., 5, 64-77.

Herold, M., Goldstein, N. C., \& Clarke, K. C., 2003. The spatiotemporal form of urban growth: Measurement, analysis and modeling. Remote Sensing of Environment, 86(3), 286-302. http://doi.org/10.1016/S0034-4257(03)00075-0

Pontius, R. G., \& Gilmore Pontius, Robert, J., 2000. Quantification error versus location error in comparison of categorical maps. Photogrammetric Engineering and Remote Sensing. http://doi.org/Cited By (since 1996) 180

R.R. Regmi, S.K. Saha, M. K. B., 2014. Geospatial Analysis of Land Use Land Cover Change Modeling at Phewa Lake Watershed of Nepal by using Cellular Automata Markov Model. International Journal of Current Engineering and Technology, 4(1), pp. 260-267.

Sakieh, Y., Amiri, B. J., Danekar, A., Feghhi, J., \& Dezhkam, S., 2014. Simulating urban expansion and scenario prediction using a cellular automata urban growth model, SLEUTH, through a case study of Karaj City, Iran. Journal of Housing and the Built Environment, 30(4), 591-611. http://doi.org/10.1007/s10901014-9432-3

Sang, L., Zhang, C., Yang, J., Zhu, D., \& Yun, W., 2011. Simulation of land use spatial pattern of towns and villages based on CA-Markov model. Mathematical and Computer Modeling, 54(3-4), 938-943. http://doi.org/10.1016/j.mcm.2010.11.019

Sun, H., Forsythe, W., \& Waters, N., 2007. Modeling urban land use change and urban sprawl: Calgary, Alberta, Canada. Networks and Spatial Economics, 7(4), 353-376. http://doi.org/10.1007/s11067-007-9030-y

Tewolde, M. G., \& Cabral, P., 2011. Urban sprawl analysis and modeling in Asmara, Eritrea. Remote Sensing, 3(10), 2148-2165. http://doi.org/10.3390/rs3102148
Thapa, R. B., \& Murayama, Y., 2010. Drivers of urban growth in the Kathmandu valley, Nepal: Examining the efficacy of the analytic hierarchy process. Applied Geography, 30(1), 70-83. http://doi.org/10.1016/j.apgeog.2009.10.002

Thapa, R. B., \& Murayama, Y., 2011. Urban growth modeling of Kathmandu metropolitan region, Nepal. Computers, Environment and Urban Systems, 35(1), 25-34. http://doi.org/10.1016/j.compenvurbsys.2010.07.005

World Urbanization 2014. https://esa.un.org/unpd/wup/ (12 Dec 2016)

Yeh, A.G.O., and Li, X., 2001. Measurement and Monitoring of Urban Sprawl in a Rapidly Growing Region Using Entropy. Photogrammetric Engineering and Remote Sensing, 67; 83-90.

Zhang, H., Jin, X., Wang, L., Zhou, Y., \& Shu, B., 2014. Multiagent based modeling of spatiotemporal dynamical urban growth in developing countries: simulating future scenarios of Lianyungang city, China. Stochastic Environmental Research and Risk Assessment, 29(1), 63-78. http://doi.org/10.1007/s00477-014-0942-z 